\title{
Pedophilia and \\ Computer-Generated Child Pornography
}

\author{
Ole Martin Moen and Aksel Braanen Sterri \\ University of Oslo
}

Citation: Moen, Ole M., Sterri, Aksel B. (2018). "Pedophilia and Computer-Generated Child Pornography, in D. Boonin (ed.), The Palgrave Handbook of Philosophy and Public Policy, pp. 369-381. https://doi.org/10.1007/978-3-319-93907-0_29.

To be a pedophile, according to the World Health Organization, is to have a sexual preference for children, boys or girls or both, usually of prepubertal or early pubertal age. ${ }^{1}$ Pedophilia is widespread -- approximately two percent of the adult population is primarily sexually attracted to children ${ }^{2}$-- and worldwide, approximately one in five girls, and one in twelve boys, are victims of sexual abuse. ${ }^{3}$

Most researchers working on pedophilia are psychologists, psychiatrists, and criminologists. How might ethicists contribute to the discussion? In this paper we ask, and seek to answer, three distinctively ethical questions about pedophilia: (1) Is it immoral to be a pedophile? (2) Is it immoral for pedophiles to seek out sexual contact with children? (3) Is it immoral for pedophiles to satisfy their sexual preferences by using computer generated graphics, sex dolls, and/or sex robots that mimic children? We hope to show, through our discussion of these questions, that an ethical investigation of pedophilia can help advance our understanding of how pedophilia should be understood, assessed, and handled.

\section{Is it immoral to be a pedophile?}

Notice that according to the World Health Organization's definition above, to be a pedophile is not the same as pursuing sexual contact with children. To be a pedophile is to have $a$ sexual preference for children, but to have a preference is not the same as acting on that

\footnotetext{
${ }^{1}$ World Health Organization, International Statistical Classification of Diseases and Related Health Problems 10th Revision (ICD-10), Section F65.4.

${ }^{2}$ Wesley Stephenson, "How many men are paedophiles?”, BBC News Magazine, July 302014 , www.bbc.com/news/magazine-28526106. Studies indicate, however, that around 5\% of men, or slightly less than that, are to some extent sexually attracted to children. See John Briere and Marsha Runtz, "University Males' Sexual Interest in Children: Predicting Potential Indices of 'Pedophilia' in a Non-Forensic Sample." Child Abuse and Neglect 13, no. 1 (1989): 65-75; Kathryn Becker-Blease, Daniel Friend, and Jennifer J. Freyd, "Child Sex Abuse Perpetrators Among Male University Students." Presentation at 22nd Annual Meeting of the International Society for Traumatic Stress Studies, Hollywood; CA, Nov November 4-7, 2006; Nathaniel McCognathy, "Pedophilia: A Report of the Evidence," Australian and New Zealand Journal of Psychiatry 32 (1998): 252-265; Michael C. Seto, "Pedophilia." Annual Review of Clinical Psychology 5 (2009): 391-407. ${ }^{3}$ Noemí Pereda, Georgina Guilera, Maria Forns, and Juana Gómez-Benito, "The Prevalence of Child Sexual Abuse in Community and Student Samples: A Meta-analysis," Clinical Psychology Review 29, no. 4 (2009): 328-338.
} 
preference. Our first aim in this paper is to discuss the moral status of merely being a pedophile.

There is little doubt that it is very unfortunate that some adults are sexually attracted to children. The fact that a trait is unfortunate, however, is not alone sufficient to make us justified in concluding that it is immoral to have that trait. We usually take for granted that for something to be immoral it must, in addition to being unfortunate, be something that, in some sense, we control or choose. Having a serious contagious disease can be unfortunate indeed, but if a person had no control over the circumstances that brought about the disease it would be wrong to conclude that he or she was guilty of moral wrongdoing.

Do pedophiles control the circumstances that make them pedophiles? Nothing indicates that they do. The competing scientific explanations of pedophilia are conditioning, childhood sexual abuse, and neurodevelopmental disorders. In terms of how pedophilia is described from the first-person perspective, pedophiles typically report that they discover their sexual preference (usually in their teens), not that they choose it, and once someone is a pedophile there is little evidence to suggest that it is any easier for them to choose to be sexually attracted to adults than it is for those of us who are not pedophiles to choose to be sexually attracted to children. ${ }^{4}$ Being a pedophile is also highly disadvantageous, so it is puzzling, on a more general level, why anyone would choose to have a pedophilic preference in the first place, given that they could. Although this issue cannot be settled here, it seems most plausible that pedophiles do not choose their preferences, and that although their preferences might well be unfortunate and perhaps also count as a disease, the mere fact of being sexually attracted to children is in itself neither moral nor immoral.

\section{Is it immoral for pedophiles to seek sexual contact with children?}

Even if we grant that it is not immoral simply to be a pedophile, it might still be immoral for pedophiles to seek sexual contact with children. To do so is an action, or a series of actions, and actions are subject to moral assessment. We shall now examine two arguments as to why it is immoral for pedophiles to engage in adult-child sex: the harm argument and the consent argument.

\section{The Harm Argument}

The harm argument is a simple argument with two premises: An empirical premise, that adult-child sex seriously harms children, and a normative premise, that it is immoral to seriously harm children. We shall simply take for granted the uncontroversial normative premise that it is immoral to seriously harm children, at least if the reason is that it gives an adult sexual pleasure. The relevant question then becomes: Does adult-child sex harm children?

In order to find out, it might be useful to distinguish between bodily and psychological harm. If small children are penetrated, or otherwise raped, they have a significant chance of suffering bodily harms. So much is indeed uncontroversial, so we shall

\footnotetext{
${ }^{4}$ For an overview see Michael C. Seto, Pedophilia and Sexual Offending Against Children: Theory, Assessment, and Intervention (Washington, DC: American Psychological Association, 2007).
} 
take it for granted. Most adult-child sex, however, does not involve violence or penetration. Though there are many tragic counterexamples, the most characteristic pedophile activities are cuddling, caressing, and genital fondling, and when full intercourse takes place, it occurs most commonly when the child is well into adolescence. ${ }^{5}$ It seems hard to argue that cuddling, caressing, and fondling cause physical harm to children's bodies, so if we think that these cases are problematic as well, then the harms to which we appeal must, at least in part, be psychological.

A look at the correlations between being a victim of childhood sexual abuse and suffering from psychological hardships seems to indicate that adult-child sex psychologically harmful. Meta-analyses estimate that between 51 and 79 percent of sexually abused children display symptoms of psychological disorders. ${ }^{6}$ Childhood sexual abuse is found to be correlated with an increased likelihood of drug dependence, alcohol dependence, major depression, general anxiety disorder, and other psychological disorders. ${ }^{7}$

But do we know that the adult-child sex causes the harm? One argument that this need not be the case is that the correlation might be explained by genetic or environmental factors that make some children more likely both to be abused and to have psychological disorders. Child abuse often happen in families that have other problems, so direct causality between child sexual abuse and later maladjustment cannot be inferred. ${ }^{8}$ There is, however, some evidence that point in the direction of causality. In cases where only one out of two twins has been sexually abused, the one that is sexually abused has a significantly higher risk of depression, alcohol and nicotine dependence, and conduct disorders. ${ }^{9}$ Moreover, when we control for genetic predispositions to depression, the correlation between adult-child sex and symptoms of antisocial personality, depression, and substance use still holds. ${ }^{10}$

These results indicate that adult-child sex causes psychological harm. Philosopher Robert Ehman has argued, however, that adult-child sex causes psychological harm only, or predominantly, because of society's way of viewing and handling sexual contact between adults and children. The harm, Ehman suggests, is the result of a self-fulfilling prophecy. In his view, adult-child sex is made traumatizing by a culture that labels it with strongly evaluative terms such as "abuse," "assault," and "molestation," and communicates to children that they have been scarred for life. ${ }^{11}$

\footnotetext{
${ }^{5}$ Dennis Howitt, Paedophiles and Sexual Offences Against Children (Chichester: Wiley, 1995), Chap. 2.

${ }^{6}$ Gail Hornor, "Child sexual abuse: Consequences and implications," Journal of Pediatric Health Care 24 no. 6 (2010): 358-364.

${ }^{7}$ Patrick Zickler, “Childhood Sex Abuse Increases Risk for Drug Dependence in Adult Women,” National Institute of Drug Abuse Notes 17 no. 1 (2002): 5.

${ }^{8}$ Heather M. Ulrich, Mickey Randolph, and Shawn Acheson, "Child Sexual Abuse: A Replication of the Meta-analytic Examination of Child Sexual Abuse by Rind, Tromovitch, and Bauserman," The Scientific Review of Mental Health Practice 4, no. 2 (June 2005): 37-51.

${ }^{9}$ Elliott C. Nelson, et.al., "Association between self-reported childhood sexual abuse and adverse psychosocial outcomes: Results from a twin study." Archives of General Psychiatry 59 (2002): 139-146.

${ }^{10}$ Steven Beach, et.al., "Impact of child sex abuse on adult psychopathology: a genetically and epigenetically informed investigation," Journal of Family Psychology 27, no. 1 (Feb 2013): 8.

${ }^{11}$ Robert Ehman, "Adult-Child Sex" in Philosophy and Sex, 2nd ed., edited by Robert Baker and Frederick Elliston (Buffalo, N.Y.: Prometheus, 1984), 435-36.
} 
The stigma associated with being a victim of childhood sexual abuse can clearly make an harmful situation even worse. ${ }^{12}$ This is in line with research by Susan Clancy, which indicates that victims of child sexual abuse typically do not suffer psychological problems because the abuse was traumatizing when it happened, but rather, that the abuse tends to become a problem later on when the memories are processed and examined, and the actions more fully understood. ${ }^{13}$ On the other hand, a study by Michael De Bellis, Eve G. Spratt, and Stephen R. Hooper concludes that "PTSD is commonly seen in sexually-abused children, especially during the period immediately following maltreatment disclosure." 14 Even if many victims of child sexual abuse do not remember the event as being traumatic at the time, as Clancey's research indicates, this does not exclude it from having had a negative impact on them. It is also important to keep in mind that even if we were to accept that most of the harms occur as a result of cultural attitudes, the harm is nevertheless real.

What Ehman might be right in claiming, however, is that not all instances of adult-child sex is harmful to the child. In an influential meta-analysis of 59 studies on college students, Bruce Rind, Philip Tromovitch, and Robert Bauserman looked not merely for harm or lack of harm, but also for reports of positive experiences. They found that a minority of college students who had had sexual contact with an adult when they were children retrospectively described this experience as positive. They also found that the extent of psychological damage depended heavily on whether or not the incident(s) were retrospectively described as "consensual."15 For "consenting" males, the psychological outcomes "were no different from those in control groups." Although the Rind study is controversial, the main findings have held up when replicated. ${ }^{16}$

A few points are worth making in this regard. Given the significant harms that do occur, the fact that some children might not be harmed - and that a minority reports that their sexual experiences were positive - fails to establish that harm is not an expected result from adult-child sex. A useful parallel to engagement in adult-child sex might be to give children hard drugs. Even if we concede that giving children hard drugs might sometimes end well, and even if we discovered that a minority later on reported that being given hard drugs was in sum a positive experience, it can still be true that harm should be expected and that, in some cases, devastating harm will be the result.

Stephen Kershnar objects to this line of argument by pointing out that that expected harm from adult-child sex in general fails to establish expected harm in all variants of adult-child sex. Based on the Rind study one might be tempted to conclude that consensual sex with boys is relatively harmless. ${ }^{17}$ Although Kershnar is right that we need to single out

\footnotetext{
${ }^{12}$ Mie F. Nielsen, "When Compassion is Making It Worse: Social Dynamics of Tabooing Victims of Child Sexual Abuse," Sexuality \& Culture 20, No. 2 (June 2016): 386-402.

${ }^{13}$ Susan A. Clancy, The Trauma Myth (New York: Basic Books, 2011).

${ }^{14}$ De Bellis, Michael D., Eve G. Spratt, and Stephen R. Hooper, "Neurodevelopmental Biology Associated With Sexual Abuse," Journal of Child Dexual Abuse 20, No. 5 (2011): 548-587.

${ }^{15}$ Bruce Rind, Philip Tromovitch and Robert Bauserman, "A Meta-Analytic Examination of Assumed Properties of Child Sexual Abuse Using College Samples," Psychological Bulletin 124, no. 1 (1998): 22-53.

${ }^{16}$ Ulrich, et.al.,"Child Sexual Abuse," 37-51.

${ }^{17}$ Stephen Kershner, Pedophilia and Adult-Child Sex: A Philosophical Analysis (Lanham, Maryland: Lexington Books, 2015, 83 .
} 
the relevant class of acts when we assign expected harm, the uncertainty involved in classifying acts can cut both ways, since a pedophile might be lead by self-serving biases to conclude that this specific act is not harmful even though it might be. We should be wary of drawing too strong conclusions from Rind's study. Rind drew his sample exclusively from American college students, but college students are not necessarily representative of the general population. ${ }^{18}$ Most obviously, those who were harmed significantly by adult-child sex might expected to be less likely to go to college. ${ }^{19}$

In light of this, we must, for the harm argument to remain convincing, reformulate it in terms of risk of harm. The empirical premise, on this variant of the argument is that adult-child sex exposes children to a high risk of being seriously harmed. The normative premise is that it is morally wrong to expose children to a high risk of being seriously harmed (absent very strong overriding reasons to the contrary). If we accept both of these premises, as it seems that we should, we have a sound argument as to why it is wrong for pedophiles to engage in adult-child sex.

\section{The Consent Argument}

Another common argument as to why it is warong for to engage in adult-child sex is the consent argument. This argument can also be formulated in terms of two premises: First, that it is immoral to engage in sex without consent; second, that children cannot consent to sex, and therefore, that sex involving children becomes non-consensual.

The consent argument has strong intuitive appeal. David Finkelhor, one of the world's leading pedophilia researchers, makes the case that the consent argument is even stronger than the harm argument. The reason, he explains, is that the harm argument is empirically vulnerable: It depends on the empirical fact of harm, which in some cases is questionable. The consent argument, by contrast, does not to the same extent depend on uncertain empirical facts. Therefore the consent argument appears to be more robust. ${ }^{20}$

Although Finkelhor is right that the harm argument is empirically vulnerable, we think he is wrong in concluding that the consent argument is any less vulnerable. The reason is that the consent argument is dependent on the harm argument. To see why, consider first the mundane fact that there are many things to which children may rightfully consent. If a father asks his 10-year-old son if they should go play basketball, and the son says yes - and they then go on to play basketball—nothing wrong has happened. The same would be true for going on a ski trip, watching a children's movie, or baking a cake. On the other hand, there are things to which children may not consent. If the father suggested that he and his son go play with guns, get drunk, or have sex, it would not be permissible to follow through on these suggestions, irrespective of whether the son said yes or no.

\footnotetext{
${ }^{18}$ Joseph Henrich, Steven J. Heine, and Ara Norenzayan, “The weirdest people in the world?”, Behavioral and Brain Sciences 33, No. 1-2 (June 2010): 61-83.

${ }^{19}$ Stephanie Dallam et.al., "The effects of childhood sexual abuse: A critique of Rind, Tromovitch and Bauserman," Psychological Bulletin 127, No. 6 (2001): 715-33.

${ }^{20}$ David Finkelhor, "What's Wrong With Sex Between Adults and Children?," American Journal of

Orthopsychiatry 49, No. 4 (1979): 692-697.
} 
Why may children consent to some things but not to other things? The central explanation seems to be that some things are harmful, and other things are not, and that while adults have the privilege to consent to harmful things (within certain limits), children do not have the same privilege, or do not have it to the same extent. The reason the consent argument depends on the harm argument, therefore, is that only if the harm argument is sound do we have a good explanation of why children cannot rightfully consent to sex. Had adult-child sex posed no risk of harm at all, it is unclear why children could not consent to it. 21

Perhaps it could be suggested that children cannot consent to sex because they are not sufficiently physically and psychologically developed to know what they are consenting to if they consent to sex. ${ }^{22}$ True as this might be, in the absence of any risk of harm, this does not seem to be problematic either. If a 10-year old boy ventured to read Hegel, it is evident that he would not be sufficiently developed to know what he was doing. Still, since this would presumably not expose him to any significant risk of harm, there would be nothing wrong in letting him do so. ${ }^{23}$

Even though consent argument depends on the harm argument, however, it does not follow that the consent argument is eliminated. We would like to argue, on the contrary, that the harm argument vindicates the consent argument in that it provides an explanation of why sex is something to which children, given their level of autonomy and understanding, cannot consent. Still, within the scope of the present discussion, the consent argument does not add much either. While the harm argument states that it is wrong to expose a child to a significant risk of serious harm, the consent argument states that this is wrong even if the child consents. Since this is already implicit in the harm argument, we conclude that it is the harm argument that provides the central explanation of why it is wrong for pedophiles to engage in adult-child sex.

\section{Is it immoral for pedophiles to use child sex dolls and computer-generated child pornography?}

So far we have considered the ethical status of being a pedophile and of engaging in adult-child sex. How, however, should we assess ways of satisfying pedophilic preferences that do not involve any actual children, such as the use of computer generated graphics that depict children, child sex dolls, or child sex robots?

Even though most of us might think that it is less bad to engage in these surrogate activities than to engage in adult-child sex, the surrogate activities nevertheless seem problematic. But where lies the problem? The harm argument, at least in the form discussed above, seems not to apply, since presumably, mere representations of children cannot be

\footnotetext{
${ }^{21}$ For arguments along similar lines, see Kershner, Pedophilia and Adult-Child Sex, Chap. 3 and David Benatar, “Two Views of Sexual Ethics: Promiscuity Pedophilia, and Rape," Public Affairs Quarterly 16, No. 3 (July 2002): 191-201.

${ }^{22}$ Igor Primoratz, "Pedophilia,” Public Affairs Quarterly 13, No. 1 (1999): 99-110.

${ }^{23}$ It might also be argued that rights based reasons that are not cashed out in terms of harm could explain the wrongness of adult-child sex. For an argument that this attempt fails, see Kershnar, Pedophilia and Adult-Child Sex, Chap. 3-5.
} 
harmed. We will now consider two arguments that seek to establish the wrongfulness of pedophilic activities even in the absence of real children, the disrespect argument and the triggering argument.

\section{The Disrespect Argument}

According to the disrespect argument it is wrong to seek to satisfy pedophilic preferences even in the absence of real children because doing so is disrespectful and thus manifests a bad moral character. To see the force of this, imagine that you walk in on your friend and find him having sex with a child sex robot for the fun of it. Would you be upset? John Danaher argues that "those who engage in such acts either (a) directly express a deficient moral character because they desire real-world rape and child sexual abuse or (b) demonstrate a socially problematic form of moral sensitivity." 24

Let us grant, for the sake of the argument, that a practice can be made morally bad in virtue of being disrespectful or manifesting a bad moral character. Let us also grant that Danaher is right that it would be wrong for most people, including your friend, to have sex with child sex robots, for the reasons Danaher outlines. But do the same reasons apply in the case of pedophiles? Is it reasonable to claim that pedophiles "express a deficient moral character" or "demonstrate[s] a socially problematic form of moral sensitivity" if they satisfy their preferences in ways that do not involve any actual children?

Given that pedophiles have not chosen their sexual preferences, and cannot direct their preferences towards adults through an act of choice, it seems that in at least one sense, pedophiles show respect, care, and concern when they choose to abstain from seeking sexual contact with real children, using instead non-sentient surrogates even though, presumably, this is sexually suboptimal when seen from the perspective of many pedophiles. It is also important to keep in mind that even though adult-child sex harms children in real life, we cannot conclude from this that pedophiles desire to harm children, and that it is a desire to harm that they act on when using surrogates. When pedophiles themselves are asked about their intentions and motivations, at least, then rather than reporting a desire to harm, they commonly report that they fall in love with children, long for physical intimacy with children, and want their feelings to be reciprocated. ${ }^{25}$ Pedophiles desire to have sex with children, and as long as it is only a contingent fact about the world that children are harmed by adult-child sex, there is no reason to posit intentions to harm, disrespect, or expression of ill will on the part of all or even most pedophiles.

This is not to deny that, very likely there are some pedophiles who desire to harm children. Even if we were to grant that it is always wrong to seek to satisfy such desires, however, we still do not have an argument against the satisfaction of pedophilic desires in general. A desire to harm can, after all, also be a feature of adult-oriented sexual desires, but we do not think that that is sufficient to make the satisfaction of all adult-oriented sexual

\footnotetext{
${ }^{24}$ John Danaher, "Robotic Rape and Robotic Child Sexual Abuse: Should they be criminalised?", forthcoming in Criminal Law and Philosophy.

${ }^{25}$ Richard Green, "Is Pedophilia a Mental Disorder?", Archives of Sexual Behavior 31, No. 6 (2002): 467-471.
} 
desires wrong. Therefore the argument that it is wrong for pedophiles to enjoy representations of adult-child sex because doing so is disrespectful is forceful only against a sub-section of such activities.

\section{The Triggering Argument}

Another argument for why it is immoral for pedophiles to use computer generated graphics, child sex dolls, or child sex robots is that doing so can trigger their desire to engage in adult-child sex with real children.

This argument seems intuitively appealing since it is likely that repeated engagement in the simulation of an activity lowers one's barriers to engaging in in real life. Research on child sex abusers reveal that some sex offenders use pornography "as a disinhibition method prior to committing child abuse." 26

On the other hand, David Riegel has suggested that for many pedophiles, pornography is a tool that helps them redirect their urges and drives, and gives them an outlet for their sexual desires in a way that does not involve having sex with children. In an internet study he found that 84 percent of the respondents reported child erotica as a "useful [...] substitute for actual sexual contact with boys, in that their urges and drives were redirected and given an outlet that affected no other person." ${ }^{27}$ Dennis Howitt, in another study of pornography usage among pedophiles, concludes that "no clear-cut causal link has been demonstrated between ... exposure to pornography and sex crime." 28

One problem with these studies is that they are based on how pedophiles explain their past behavior to researchers, which introduces several potential sources of error. We cannot be certain that their recollection of the events is correct, or if they are reliable interpreters of their own behavior. It is also hard to know what would have happened in the absence of this stimuli. In order to correct for some of these sources of error in previous studies, Jerome Endrass et al. studied the recidivism rate in a population of people charged with possessing child pornography. The researchers tracked them for six years and found that "[c]onsuming child pornography alone is not a risk factor for committing hands-on sex offenses - at least not for those subjects who had never committed a hands-on sex offense." 29

Another piece of evidence can be found in studies of countries where access to child pornography has either gotten easier or more difficult. If access to child pornography leads to more sex abuse, we should expect the share of child sex abuse in a society to increase when more people have access to child pornography. The opposite, however, seems to be the case. Milton Diamond, Eva Jozifkova, and Petr Weis found that when the Czech Republic lifted its ban on pornography, including child pornography in 1989, there was a drop in rape and child

\footnotetext{
${ }^{26}$ Suzanne Ost, "Children at risk: legal and society perceptions of the potential threat the possession of child pornography poses to society," Journal of Law and Society 29 (2002): 449.

${ }^{27}$ David Riegel, "Effects on Boy-Attracted Pedosexual Males of Viewing Boy Erotica," Archives of Sexual Behavior 33, No. 4 (2004), p. 321-323.

${ }^{28}$ Dennis Howitt, "Pornography and the paedophile: Is it criminogenic?", British Journal of Medical Psychology 68, No. 1 (1995): 17.

${ }^{29}$ Jerome Endrass et.al., "The Consumption of Internet Child Pornography and Violent and Sex Offending," BMC Psychiatry 43, No. 9: 1.
} 
sexual abuse. ${ }^{30}$ Diamond has also found similar negative correlations between the availability of child pornography and adult-child sex in Japan, China, and United States. ${ }^{31}$ These results are also in line with the findings from an early Danish study. ${ }^{32}$ Although we might question the extent to which the correlations are indicative of causation, no studies have yet shown the opposite correlation. ${ }^{33}$

Looking at several of these studies, John Danaher concludes that " $t \mathrm{t}]$ he research on links between child pornography and real-world acts of child sexual abuse is ... mixed."34 Generalizing from this, he argues, it is unclear what would be the effect of allowing child sex robots. As the review of the research above shows, however, this is not the right conclusion to draw. There is a clear tendency in the direction of a reduction in sex child abuse when surrogate activities are accessible.

Although we do not know the extent to which what we know about access to child pornography generalizes to computer-generated graphics, sex dolls, and/or sex robots, some generalization seems likely. James Cantor, an experienced psychologist who works with child sex offenders, reports that "what I have consistently observed is that men commit their offenses when they feel the most desperate. [B]y blocking the harmless ways of masturbating, all we are doing is making them more desperate." Given the research and the mechanisms likely in play, we have most reason to conclude that access to such content will result in less adult-child sex. In the absence of convincing arguments to the contrary, we should further conclude that it can be morally permissible for pedophiles to enjoy fictional stories, sex child robots and computer-generated graphics with pedophilic content.

It is important to note, however, that even if we accept this conclusion, it does not follow that we must be comfortable with such practices or that we should not be worried in case we discovered that someone that we know enjoys engaging in activities that simulates adult-child sex. We might have good reasons to worry indeed since this is a strong indication that the person is a pedophile, and pedophilia predisposes people to seek adult-child sex, which in turn exposes children to significant risks of serious harm. Observe, however, that what is troubling in this case is the discovery of the person's sexual preferences via his enjoyment of simulated adult-child sex, not his enjoyment of the simulated adult-child sex as

\footnotetext{
${ }^{30}$ Milton Diamond, Eva Jozifkova, and Petr Weiss, "Pornography and Sex Crimes in the Czech Republic," Pornography and Sex Crimes in the Czech Republic," Archives of Sexual Behavior 40, No. 5, 1989 pp. $1037-43$. ${ }^{31}$ Milton Diamond and Ayako Uchiyama, "Pornography, Rape, and Sex Crimes in Japan," International Journal of Law and Psychiatry 22, No. 1 (1999):1-22; Milton Diamond, "The effects of pornography: An international perspective," in James E Elias, et.al (eds.), Pornography 101: Eroticism, sexuality and the first amendment, (Amherst, NY: Prometheus Press, 1999): 223-260; for an overview, see Milton Diamond, "Pornography, public acceptance and sex related crime: A review," International Journal of Law and Psychiatry 32 (2009): 304-314.

${ }^{32}$ Kutchinsky, Berl. (1973), The Effect of Easy Availability of Pornography on the Incidence of Sex Crimes: The Danish Experience. Journal of Social Issues, 29: 163-181

${ }^{33}$ A study of the expansion of the broadband net in Norway, however, shows that there might be a causal connection between access to high speed internet and sexual violence, including sexual abuse of children, possibly as a result of increased consumption of pornography. Manudeep Bhuller, Tarjei Havnes, Edwin Leuven, and Magne Mogstad, "Broadband Internet: An Information Superhighway to Sex Crime?" The Review of Economic Studies 80, No. 4 (October 1, 2013): 1237-1266.

${ }^{34}$ Danaher, "Robotic Rape and Robotic Child Sexual Abuse," forthcoming.
} 
such. Given that he has those preferences and cannot change them, he might do nothing wrong. On the contrary, he might be pursuing one of the best strategies he might pursue given the unfortunate situation in which he finds himself.

\section{Conclusion}

If our arguments in this article are sound, then being a pedophile-in the sense of having a sexual preference for children-is in itself neither moral nor immoral. Engagement in adult-child sex, however, is immoral, the reason for which is the expected harm on children. Finally, using simulations of adult-child sex is morally acceptable and might, in some cases, be the best available option. If these conclusions are correct, what practical implications follow?

One central implication is that in dealing with pedophilia, our aim should not be to find outlets for our disgust and outrage, but rather, to minimize what is the real problem: harm to children.

On the least revisionist side, the aim of reducing harm provides us with a good justification for upholding current bans on adult-child sex and the production of child pornography. There are, however, also a number of more revisionist implications. One revisionist implication is that we should abstain from condemning pedophiles unless we know that they have pursued sexual contact with children. It is gravely unjust to condemn non-offending pedophiles; many of them are perfectly good people who should indeed be praised for handling their sexuality in ways that do not harm children.

Today's widespread condemnation discourages pedophiles from telling health professionals about their attraction to children. Many pedophiles report that they do not believe that health professionals will understand their problems, and they are afraid that they will be stigmatized further if they reveal their sexual preferences. ${ }^{35}$ Insofar as detection and counseling can help prevent abuse, this is very unfortunate. Stigma is also known to lead to stigma-related stress, including social and interpersonal problems, emotional dysregulation, limited life opportunities, which in turn are theorized to be central risk factors for triggering sex offences. One important finding in this respect is that "individuals offend when they are at their most vulnerable and experience pervasive loneliness." $" 36$

In addition to providing more help and to reduce stigma, we should teach adolescents not just what to do in case they are victims of sexual abuse (which, thankfully, we have started teaching them over the last few decades), but also what to do in case they themselves are pedophiles. A certain percentage of adolescents either are or will become pedophiles, and currently they are not given any advice on how to handle their sexuality. If we believe that pedophiles, by their nature, are immoral and desire to harm children, it is understandable that we do not think that such advice would help. If, on the other hand, we believe that pedophiles, through no fault of their own, find themselves in a situation that they struggle to handle, advice on how to live as a non-offending pedophile could make big difference.

\footnotetext{
${ }^{35}$ James M. Cantor and Ian V. McPhail, "Non-Offending Pedophiles," Current Sexual Health Reports 8, No. 3 (2016): 124.

${ }^{36}$ Ibid., $123-125$.
} 
Arguably, the production, distribution, and use of computer generated graphics, child sex dolls, and child sex robots should be made legal in some form. This does not, however, entail that it should be sold over the counter. Governments should experiment with different ways to regulate such products with the goal of minimizing negative third party effects. One option is that pedophiles can be given legal access to these products if they register with a psychiatrist. We must keep in mind, however, that since many pedophiles might be reluctant to reveal their sexual preferences to a psychiatrist, and could still be helped to avoid molestation with the help of surrogates, this regulatory regime might be too strict.

In the case of pedophiles who have molested children, cognitive behavioral therapy, possibly in combination with empathy enhancing drugs like MDMA, could be used to both increase empathic understanding of the harm they inflict on children, and to learn techniques to control their urges when they are tempted to commit new crimes.

Of course, a policy plan for dealing with pedophilia requires interdisciplinary work far beyond the scope of this article. Nevertheless, we have given an outline for how pedophilia should be approached under such a plan. The aim of our social and legal treatment of pedophilia should be to minimize harm to children, and to the extent that current practices are counterproductive in this respect, we should change our ways. 